\title{
WOLTER X-RAY MICROSCOPE CALIBRATION
}

UCRL--94097

DE86 01234J

\author{
Michel Gerassimenko
}

This paper was prepared for submittal to the Society for Photo-optical Instrumentation Engineers (SPIE) 30th Annual InternationaI Technical Symposium on OpticaI and Optoelectronic Applied Sciences and Engineering, San Diego, California, August 17-22, 1986

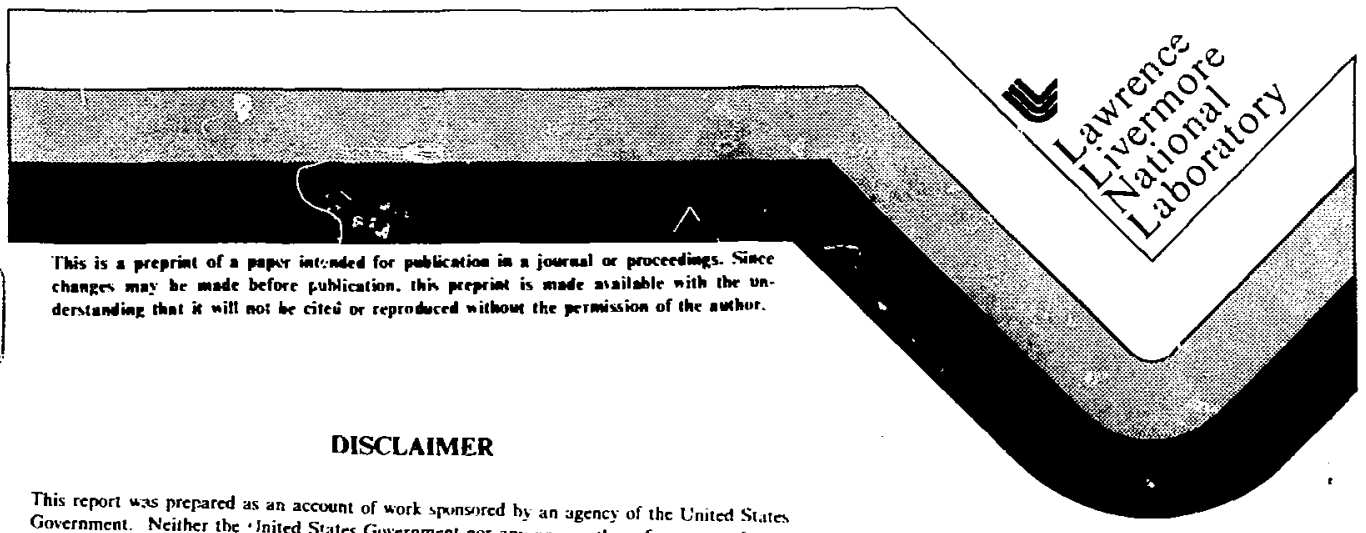

Government. Neither the Inited States Government nor by an agency of the Lnited Sitte. cmploves, makex any Harranty expess Guvernment nor any agency thercof, nur any of thair

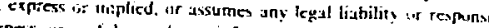

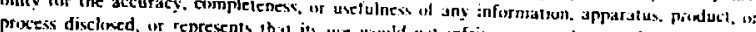

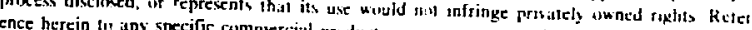

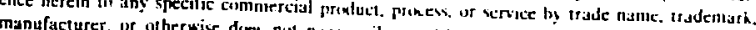

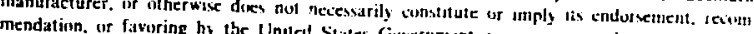

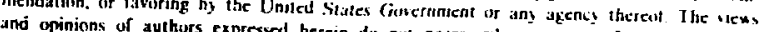

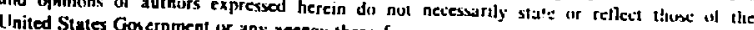
Inited States Gos ernment or any agency thereol. 


\title{
Wolter $x$-ray mictoecope calibration \\ Michel Gerauimenko \\ University of Califomia, Lawrence Livermore National Laboratory \\ Mail Stop 43, F.O. Box o06, Liventore, California 94550
}

\begin{abstract}
Abutract
A $22 \times$ Wolter microscope was calibrated after several months of operation in the Lawrence Livermore National laboratory (LLNL) Inertial Confinement Fusion program. Placing a point $x$-ray source at the microscope focus, I recorded the image plane spectrum, as well as the direct spectrum, and from the ratio of these two spectra derived an accurate estimate of the microscope solid angle in the $1-4$ keV range. The solid angle was disn caleulated using the microscope geometry and composition. Comparison of this calculated value with the solid angle that was actually measured suggests contamination of the microscope surface.
\end{abstract}

\section{Introduction}

Axisymmettic hyperboloid-ellipsoid x-ray microscopes have been used in laser fusion programs to provide high spatial resolution in the micron range with a relatively large solid angle. ${ }^{12}$ Aside from alignment issues, characterization of such a microscope entails (at the very least) spatial resolution and effective solid angle detemination. A simple method for determining the effective microscope solid angle is here applied to the $22 \times$ Wolter microscope that has been used in the LLNI. Inertiaj Confinement Fusion program.

\section{Measurement principle}

In principle, the microscope solid angle may be related to a simple ratio of incident to focal plane flux. The relation is derived as follows. Cansider a source spertrum $S(E)$ exlending beyond the high-energy cutoff in the microscope response. Jhe transmission of all filters used in the experimental setup is given by $\eta(E)$, the microscope solid angle by $\Omega$, its reflectivity by $R(E)$, and the detector response by $(E)$. The incident flux messured at energy $E$ is then given by

$$
D(E)=\int S(x) \eta(x) \epsilon(E-x) d x
$$

provided that the detector response is normalized. The spatial integral of the flux at the microscope's focal plane is

$$
F(E)=\int S(x) \eta(x) \Omega_{-1(}(x) k(E-x) d x
$$

where $\boldsymbol{\Omega}_{\text {cilf }}(x)=\boldsymbol{\Omega} \cdot R(E)$ is the effective microscope solid angle.

One of two conditions must be met if $\Omega_{\text {eff }}$ is to be related to a simple ratio of fluxes. First, if $\Omega_{\mathrm{rll}}$ in Eq. (2) varies little over the range where $\epsilon$ is significant (i.e., over the energy range of the detector resolution), it can be brought outside the integral to give

$$
\Omega_{e r i}(E)=\frac{F(E)}{D(E)} .
$$

Altematively, if $\Omega_{\text {efl }}$ varies substantially over the range where $\epsilon$ is significant, and $S$ - $\eta$ varies slowly over the same region, then

$$
\frac{F(S)}{D(E)} \simeq \int \Omega_{c-1 f}(x) \in(E-x) d x .
$$

It tums out that one or the other of these two conditions is in fact met for measurements made in the 1-4 $\mathrm{kcV}$ range distussed below. Thus, the ratio $F(E) / D(E)$ approximates the sverage value of $\Omega_{\text {etr }}(E)$ over the enengy range of the delector resolution.

\section{Measurement technique}

Figure 1 shows the physical setup for the solid-angle measurements. Duting normal operation a pre-fiter is placed in front of the electroless nickel microscope to protect it from tangel debris. In order to match these operational conditions, a pre-filter is installed for the calibration as well. The source is positioned $2915 \mathrm{~mm}$ in front or the microscope.

The $x$-ray source illuminatieg the microscope must be sufficiently small to fit within the instrument's field of view: it must also produce $x$-rays over the energy range of interest. The fow-energy limit is set at about $1 \mathrm{keV}$ by the pre-filter transmission, while the high-erergy limit is about t keV. This is the level at whici reflectivity becomes negligible for the electroless nickel.

The point source described in Price, Boyle, and Glaros meets these requirements. ${ }^{3}$ It consists of a single-turn filament and a tungsten needle that is operated at several $\mathrm{kV}$. With a focal plane image that is roughly $400 \mu$ in diameter, the source size is deduced to be about $20 \mu$. A $5 k$ ketch of the $x$-ray source is shown in Figure 2 


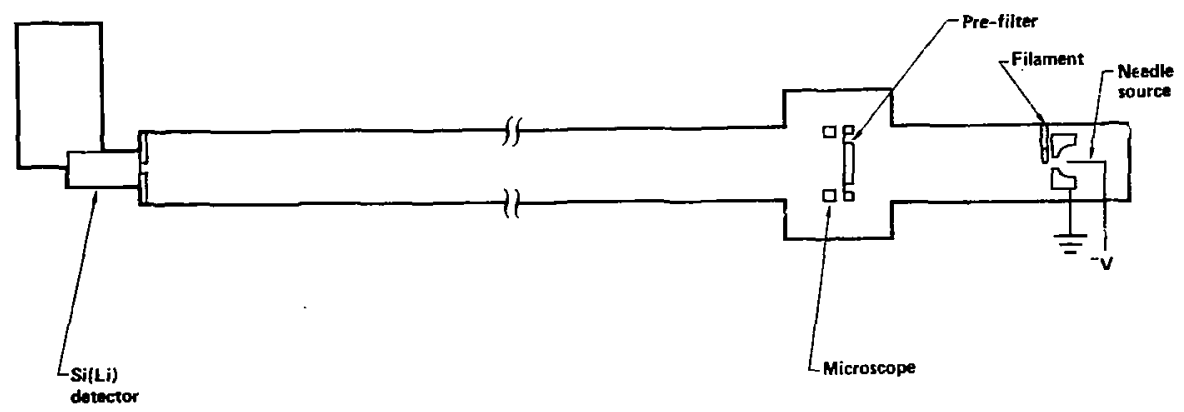

Figure 1. The experimental setup for solid-angle measurements.

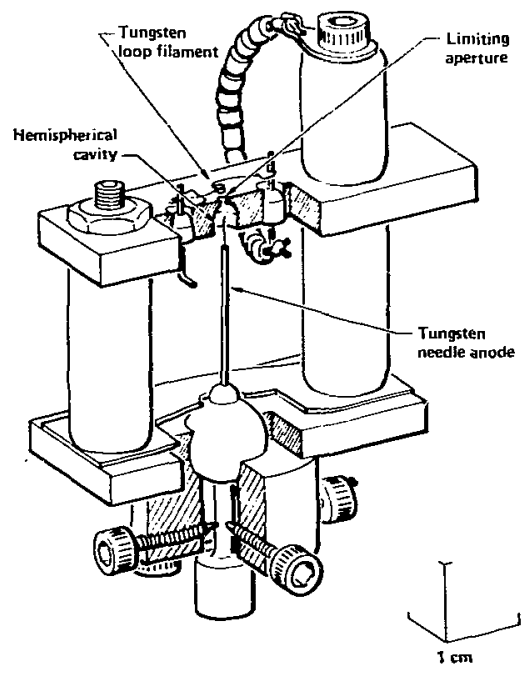

Figure 2 X-ray point source assembly (after Price, Boyle, and Glaros $)$. Since the focal plane image measured $400 \mu$ in diameter, the source size is deduced to be roughly $20 \mu$. 
A Si(L) detector is used to measure the x-ray source spectrum D(F). This spectrum (shown in Figure 3) is relatively $\Omega$ at in the 1-4 keV range except for the turgsion $M$ line at $1.77 \mathrm{keV}$. The full width half maximum detector resolution at the line energy is $150 \mathrm{eV}$. Fortunately, for two reflections at the $1 \mathrm{deg}$ angle used in the microscorz, the alculated reflectivity of electroless nickel varios slowly between 1.5 and 2 keV (Figure 4 ). Reflectivity is calculated using the composition of the microscope material (87\% nickel by weight with the balance phosphorus at an overall density of $\left.7.9 \mathrm{~g} / \mathrm{cm}^{3}\right)$ and tabulated constants.

The focal plane spectrum $F(E)$ is displayed in Figure 5, and some experimental parameters are listed in Table 1. Energy calibration of the multichannel analyzer is deduced from the measured position of the tungsten $M$ line, and the position of the Se Ka line was obtained during a calibration run.

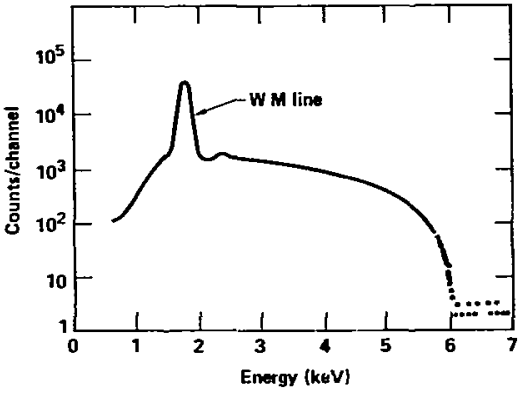

Figure 3. Source spectrum D(E) incident upon the microscope. Parameters of the Si(L) detector system a re listed in Table $\mathrm{I}$. under the heading "Instrument Setlings."

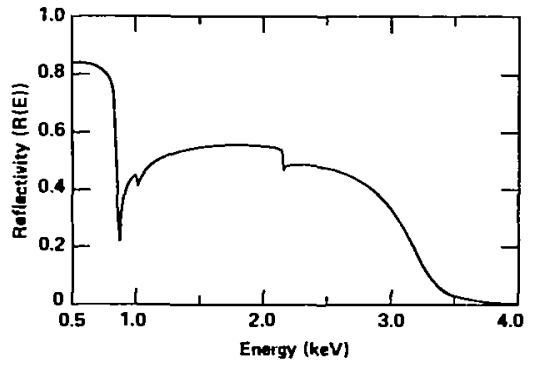

Figure 4. Reflectivity of electroless nickel for two reflections at 1 deg. calculated using the data supplied in Reference 4.

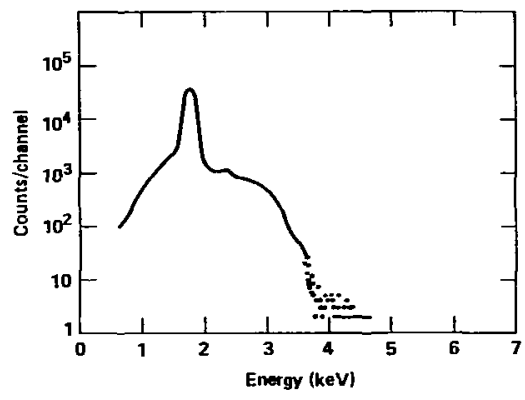

Figure 5. Focal plane spectrum $F(E)$. Detector system parameters are listed in Table 1 under the heading. "Instrumrnt Settings." 
Table 1. Calibration Parameters

\begin{tabular}{|c|c|c|}
\hline Source & & \\
\hline \multirow{3}{*}{$\begin{array}{l}\text { Needle: } 6 \text { deg cone anglo } \\
\text { Filament: } 1 \text { tum, } 20 \text { mils ID } \\
\text { Needle tip to base front: } 1 \mathrm{~mm} \\
\text { Spot size in microscope image plane: } 0.4-\mathrm{mm} \text { dianteter }\end{array}$} & \multirow{2}{*}{\multicolumn{2}{|c|}{$\begin{array}{l}\text { Kevex } \operatorname{Si}(\mathrm{Li}) \\
\quad \text { Detector bias: } 500 \mathrm{~V} \\
\text { Preamp: gain } X 4 \text {, fine gain } 0.6 \text { shaping } 6 \\
\text { SCA: } 0.25-10 \mathrm{~V} \\
\text { ND575: Conv: gain } 8 \mathrm{~K}\end{array}$}} \\
\hline & & \\
\hline & Direct Spectrum & Focal Plane Spectrum \\
\hline $\begin{array}{l}\text { Source settings: } \\
\text { SCA count rate: } \\
\text { Live time: }\end{array}$ & $\begin{array}{l}\text { skV, } 230 \mathrm{nA} \\
470 \mathrm{cts} / \mathrm{s} \\
6 \mathrm{nO0} \text { s/unit } \\
(5 \text { units acquired) }\end{array}$ & $\begin{array}{l}6 \mathrm{kV}, 150 \mathrm{n} \wedge \\
530 \mathrm{cis} / \mathrm{s} \\
6000 \mathrm{~s} / \text { unit } \\
\text { (5 unils scquired) }\end{array}$ \\
\hline Aperiute diamuter: & $1.27 \mathrm{~mm}$ & $1.27 \mathrm{~mm}$ \\
\hline Source tip to setector aperture: & $163.2 \mathrm{~mm}$ & \\
\hline
\end{tabular}

\section{Results}

The ratio $F(E) / D(E)$ as it appears in Figure 6 is a good estimate of $\Omega_{\text {dul }}$ (E). The fact that fluctuations in the data are due to count rate statistics is

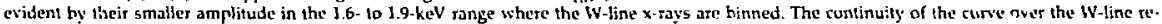
gion is an indieation of the stability in the experimental conditions achicted during the messurements.

It is interesting to compare the measured effective solid angle (Figure 6) with the calculated values [ $\boldsymbol{\Omega}_{\text {eff }}=\boldsymbol{\Omega}$. $\mathrm{R}(\mathrm{x}$ )] disp]ayed in Figure 4 . Agreement between the mejsured and calculated values is improved slightly by convolving the calculated solid angle with the detecter resolution. The resolution is taken to be Cussian with the standard deviation being a constant fraction of the enargy. Its value was fitted from the IV-line data in the direct spectrum shown in Figure 3.

The convolved calculated solid angle is shown in figure 7 , and the ratio of measured to calculated solid angles is given in Figure 8 . A small number of pulses pile up al tuice the tungsten $M$ line energy, affecting the ratio above $3.4 \mathrm{keV}$. A trend is evident in the data, one thal teveals the ratio 35 a monotonically decreasing function of energy.

The near urity ratio at $1 \mathrm{keV}$ is an indication of the smoothness of the microscope surface, since roughness produces large angle scattering. and this scattering removes energy from the integrated spectrum at the focal plane. As one moves to higher energies the ratio steadily decreases, tropping below 0.2 at $3.4 \mathrm{keV}$. This behavior sugges/s that the microscope has heen contaminated before calibration, during its months of use on the Shiva luser at LLNL. An oil film or any other organic residue admixed to the microscope surface could produse the type of energy dependence seen in the ratio. Another possible reason for the lowered ratio would be small-scale surface roughness, but comparison of the data reported here with cruder measurements performed prior to microscope instalfation favor the contamination hypothesis.

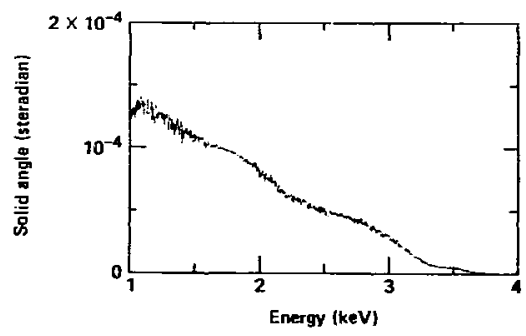

Figure 6. The ratio of $F(E) / D(E)$ provides a gool estimate of the effective microscope solid angle.

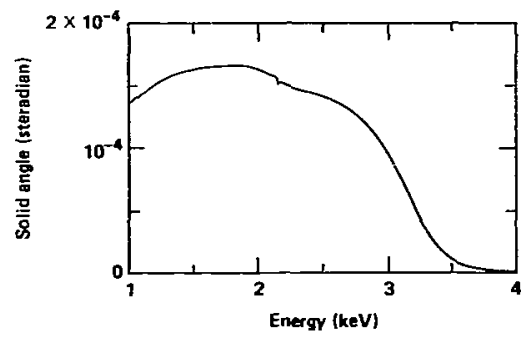

Figure 7. Calculated effective microscope solid angle using the microscope geomeby and the electroless nickel refletivity. The solid angle has been convolved with the detector resolution to give better agreement with the measured values displayed in Figure 6. 


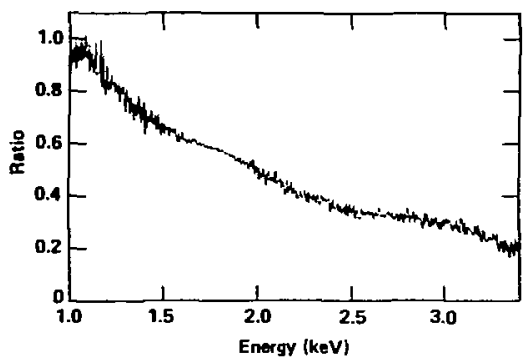

Figure 8. Ratio of measured to calculated effective microscope solid angles.

\section{Conclusion}

The faitly straightfonvard messurements of spectra incident upon the microscope and at its foral plane have yielded a reasonable estimate of the microscnpe soljd angle over its useful energy range. The messured solid angle is close to that calculated neas $\mathrm{j}$ keV, and derseases to only 1 wo lenths of the value calculated at $3.4 \mathrm{keV}$. This energy dependence was most likely caused by contamination of the microscope surface.

\section{Acknowledgments}

I am grateful to Rotwert H. Price, who hoth designed and operated the microscope, and who pionecred the ealihration stheme described in this wark. William M. Cook wiss a full participant in all phases of the characterization effort. This work was purfomed urder the auspiees of the U.S. De'purtment of Energy by the Lawrence Livermore National Laboratory under contract No. W'-7+05-Eng-48.

\section{References}

1. Price, R. H., "X-Ray Aicroscopy Using Grazing Incidence Reflection Optics," AIP Conf. Proc., Vol. 75, p. 189. 1981.

2. Otrenschain, S. P., R. R. Whitiotk. E. A. McLean, B. H. Ripin, R. H. Price, D. W. Phillion, E. M. CampbelJ, M. D. Rosen, and J. M. Auerbach, "Uniform Ablotive Acceleration of Targets by Laser Irradiation at $10^{14} \mathrm{~W} / \mathrm{cm}^{2}, "$ " Phys. Rev. Lelt., Vol. 50, No 44. 1983.

3. Price, R. H., M. J. Boyle, and S. S. Giaros, Point X-Ray Source, Lawrence Livermore National Laboratory, Livermore, CA, UCRL-81643. 1978.

4. Henke, B. L., P. Lec, T. J. Tanaka, R. L. Shimabukuro, and B. K. Fujikawa, "Low-Energy X-Ray Interaction Coeffjcients," in Atomic Data and Nudear Data Tables, Vol. 27, No. 1. 1982. 